\title{
CARRIER DETECTION OF WERNER'S SYNDROME USING A MICROSATELLITE THAT EXHIBITS LINKAGE DISEQUILIBRIUM WITH THE WERNER'S SYNDROME LOCUS
}

\author{
Koichi Kuhara, Jun Nakura, Lin Ye, Noriaki Mitsuda, \\ Kouzin Kamino, Yi ZhaO, Yoshihiko FujioKa, \\ Tetsuro Miki, and Toshio OGIHARA \\ Department of Geriatric Medicine, Osaka University Medical School, \\ 2-2 Yamadaoka, Suita, Osaka 565, Japan
}

\begin{abstract}
Summary Werner's syndrome (WS) is a rare autosomal recessive disorder, one of the progeroid syndromes, characterized by features of premature aging. The genetic defect in WS is unknown but recently the genetic linkage of WS to several markers on the short arm of chromosome 8 has been reported. Genetic analysis of 25 families with WS demonstrated that D8S339 was the closest marker linked to the gene locus for Werner's syndrome (WRN), with a peak lod score of 18.29 at recombination frequency 0.001 , and showed a linkage disequilibrium with the WRN locus. We studied two unrelated families with WS using ANK1, D8S339, and D8S360. The mutative haplotype identified through the generations in pedigrees provides a means of carrier detection and presymptomatic diagnosis.
\end{abstract}

Key Words Werner's syndrome, molecular diagnosis, microsatellite, carrier detection

\section{INTRODUCTION}

Werner's syndrome (WS) is an autosomal recessive disorder characterized by features of premature aging such as ocular cataracts, graying hair, hypogonadism, cutaneous atrophy, short stature, and osteoporosis. About $10 \%$ of patients develop neoplasia, with a particularly high frequency of sarcoma and meningioma. The mean life span of WS patients is 45-50 years and most patients die of malignant neoplasms or various forms of arteriosclerosis. The diagnosis of WS is usually made in the third decade. Skin fibroblasts from WS patients demonstrate slow growth and reduced life span in vitro (Epstein et al., 1966). Recently the WRN

Received August 19, 1994; Revised version accepted September 22, 1994. 
locus was mapped to 8p11.2-p12, and several microsatellite markers such as ANK1, D8S87, and D8S339 were reported to be closely linked to the WRN locus (Goto et al., 1992; Schellenberg et al., 1992; Thomas et al., 1993; Yu et al., 1994). We examined 25 unrelated families with WS using D8S339, and demonstrated that D8S339 was the closest marker linked to the WRN locus and exhibited linkage disequilibrium with the WRN locus. Since heterozygous carriers with WS mutation are apparently normal and healthy, it is difficult to differentiate them from among members of WS families by clinical examination only. In two unrelated families we examined 4 patients and 2 apparently normal siblings. Haplotyping of the WRN region provides a means of carrier detection and presymptomatic diagnosis.

\section{MATERIALS AND METHODS}

Subjects and diagnosis. We studied 36 members from 25 Japanese families. In 20 Japanese families, only one first or second cousin patient was analyzed. Two unrelated families were from more complicated inbred pedigrees. In the remaining 3 families, affected and unaffected siblings or both parents were genotyped. Parents of $O$ family (No. 18 family) were from a first cousin marriage. It is not clear whether the parents of $\mathrm{H}$ family (No. 22 family) were from a consanguineous marriage. All patients defined as WS satisfied the criteria for WS proposed by Nakura et al. (1994).

Preparation of DNA and PCR assays. DNA was prepared from peripheral blood leukocytes according to standard protocols. We used ANK1, D8S339, and D8S360 for DNA markers on the short arm of chromosome 8 (Polymeropoulos et al., 1991; Thomas et al., 1993; Kamino et al., 1993). These markers are located on the small region with the order cen-ANK1-6cM-(D8S339, WRN)11.5 cM-D8S360-tel (Nakura, unpublished data). The accurate order of D8S339 and WRN was obscure. We synthesized PCR primers for each marker. PCR reaction was carried out in a total volume of $10 \mu \mathrm{l}$ containing $50 \mathrm{ng}$ of genomic DNA, 4 pmol of one unlabeled primer, 4 pmol of a ${ }^{32} \mathrm{P}-\mathrm{ATP}$ end-labeled primer $(0.2 \mu \mathrm{Ci}), 200 \mu \mathrm{M} \mathrm{dNTP}, 1 \%$ formamide, $1.5 \mathrm{mM} \mathrm{MgCl}_{2}, 50 \mathrm{~mm} \mathrm{KCl}, 10 \mathrm{~mm}$ Tris$\mathrm{HCl}$ at $\mathrm{pH} 8.4$ and $0.25 \mathrm{U}$ Taq polymerase, using Perkin Elmer Cetus Thermal Cycler for 35 cycles as follows: $94^{\circ} \mathrm{C}$ for $45 \mathrm{sec}$, annealing temperature for each primer for $30 \mathrm{sec}$, and $72^{\circ} \mathrm{C}$ for $30 \mathrm{sec}$ for each cycle. The amplified product was fractionated in a $6 \%$ polyacrylamide gel containing $30 \%$ formamide and visualized by autoradiography. The size of the alleles was determined by comparison to M13mp18 DNA sequencing ladders.

Linkage analysis and linkage disequilibrium tests. Linkage analysis was performed using the computer program LINKAGE version 5.1 (Lathrop et al., 1984). It was assumed that the gene frequency of WRN was 0.004 and the disease was inherited in an autosomal recessive fashion with complete penetrance (Epstein 
et al., 1966). Allele frequency of three microsatellites for lod score calculation was from 50 Japanese controls. Analysis of linkage disequilibrium association between alleles at the WRN locus vs. D8S339 was performed by $\chi^{2}$ test.

\section{RESULTS}

Allele frequency and two-point linkage analysis

The gene frequency for ANK1 and D8S360 in the Japanese population has been reported by Nakura et al. (1993) and Kamino et al. (1993). In this study we obtained the gene frequency for D8S339 (Table 1). Twenty-five families were typed for D8S339. All of the patients showed homozygosity for this marker except one first cousin patient. This fact means that there was at least one obligate recombination in 25 families. Table 2 shows the combined lod score between the WRN locus and D8S339. Peak lod score was 18.29 at recombination frequency 0.001, suggesting that D8S339 is the closest marker to the WRN locus. For individuals from these 24 families showing homozygous genotype, only a single chromosome was counted in determining the marker allele frequencies on the disease chromosome. For individuals from No. 25 family showing heterozygous genotype, both marker alleles were counted. Allele G of D8S339 accounted for $50 \%$ of the WRN chromosomes, but only $13 \%$ of the control chromosomes. D8S339 showed a strong linkage disequilibrium with the WRN locus $\left(\chi^{2}=26.38\right.$, $\mathrm{p}<0.005)$.

\section{Haplotyping the families}

To determine the haplotype, 8 members from 2 families were genotyped using three microsatellites, D8S360, D8S339, and ANK1 (Fig. 1). Figure 2 shows the results of genotyping of WS families. In $\mathrm{O}$ family, the parents were consanguineous and were asymptomatic carriers. II- 1 and II-2 were patients and shared the same mutative haplotype, D-G-A. Their younger sister II-3 was normal and healthy. It was not clear whether she had received one mutative allele from the parents, because we did not exclude the possibility that a recombination had occurred between D8S339 and ANK1 in either haplotype D-F-A or haplotype F-F-A. A1though we did not obtain DNA samples from the parents, their haplotypes can be deduced from those of their children. In $\mathrm{H}$ family, the parents' marriage

Table 1. D8S339 (WT251) allele frequency.

\begin{tabular}{lcccccccccc}
\hline & A & B & C & D & E & F & G & H & I & J \\
\hline bp & 162 & 164 & 166 & 168 & 170 & 172 & 174 & 176 & 178 & 180 \\
Control & 0.32 & 0.05 & 0.00 & 0.00 & 0.00 & 0.37 & 0.13 & 0.09 & 0.01 & 0.03 \\
WS & 0.23 & 0.11 & 0.00 & 0.00 & 0.00 & 0.00 & 0.50 & 0.08 & 0.04 & 0.04 \\
\hline
\end{tabular}

Number of chromosomes: Control $=100, \mathrm{WS}=26, \chi^{2}=26.38, \mathrm{p}<0.005$. 
Table 2. Genotype and pairwise lod scores between WRN locus and D8\$339 (WT251) in WRN families.

\begin{tabular}{|c|c|c|c|c|c|c|c|c|c|}
\hline \multirow{3}{*}{$\begin{array}{c}\text { No. } \\
1\end{array}$} & \multirow{2}{*}{\multicolumn{2}{|c|}{ Alleles }} & \multicolumn{7}{|c|}{ Recombination frequency } \\
\hline & & & \multirow{2}{*}{$\frac{0.001}{0.42}$} & \multirow{2}{*}{$\frac{0.01}{0.41}$} & \multirow{2}{*}{$\begin{array}{r}0.05 \\
0.34\end{array}$} & \multirow{2}{*}{$\frac{0.10}{0.27}$} & \multirow{2}{*}{$\begin{array}{l}0.20 \\
0.15\end{array}$} & \multirow{2}{*}{$\frac{0.30}{0.07}$} & \multirow{2}{*}{$\begin{array}{l}0.40 \\
0.03\end{array}$} \\
\hline & $\mathrm{FC}$ & $\mathrm{A} / \mathrm{A}$ & & & & & & & \\
\hline 2 & $\mathrm{FC}$ & $\mathrm{A} / \mathrm{A}$ & 0.42 & 0.41 & 0.34 & 0.27 & 0.15 & 0.07 & 0.03 \\
\hline 3 & $\mathrm{FC}$ & $\mathrm{A} / \mathrm{A}$ & 0.42 & 0.41 & 0.34 & 0.27 & 0.15 & 0.07 & 0.03 \\
\hline 4 & $\mathrm{FC}$ & $\mathrm{A} / \mathrm{A}$ & 0.42 & 0.41 & 0.34 & 0.27 & 0.15 & 0.07 & 0.03 \\
\hline 5 & FC & $\mathrm{A} / \mathrm{A}$ & 0.42 & 0.41 & 0.34 & 0.27 & 0.15 & 0.07 & 0.03 \\
\hline 6 & COM & $\mathrm{A} / \mathrm{A}$ & 0.44 & 0.42 & 0.34 & 0.25 & 0.12 & 0.05 & 0.02 \\
\hline 7 & $\mathrm{FC}$ & $\mathrm{B} / \mathrm{B}$ & 0.94 & 0.91 & 0.81 & 0.69 & 0.46 & 0.26 & 0.11 \\
\hline 8 & $\mathrm{SC}$ & $\mathrm{B} / \mathrm{B}$ & 1.10 & 1.06 & 0.93 & 0.77 & 0.48 & 0.24 & 0.09 \\
\hline 9 & $\mathrm{SC}$ & $\mathrm{B} / \mathrm{B}$ & 1.10 & 1.06 & 0.93 & 0.77 & 0.48 & 0.24 & 0.09 \\
\hline 10 & $\mathrm{FC}$ & $\mathrm{G} / \mathrm{G}$ & 0.71 & 0.69 & 0.60 & 0.50 & 0.30 & 0.16 & 0.06 \\
\hline 11 & $\mathrm{FC}$ & $\mathrm{G} / \mathrm{G}$ & 0.71 & 0.69 & 0.60 & 0.50 & 0.30 & 0.16 & 0.06 \\
\hline 12 & $\mathrm{FC}$ & $\mathrm{G} / \mathrm{G}$ & 0.71 & 0.69 & 0.60 & 0.50 & 0.30 & 0.16 & 0.06 \\
\hline 13 & $\mathrm{FC}$ & $\mathrm{G} / \mathrm{G}$ & 0.71 & 0.69 & 0,60 & 0.50 & 0.30 & 0.16 & 0.06 \\
\hline 14 & $\mathrm{FC}$ & $\mathrm{G} / \mathrm{G}$ & 0.71 & 0.69 & 0.60 & 0.50 & 0.30 & 0.16 & 0.06 \\
\hline 15 & $\mathrm{FC}$ & $\mathrm{G} / \mathrm{G}$ & 0.71 & 0.69 & 0.60 & 0.50 & 0.30 & 0.16 & 0.06 \\
\hline 16 & $\mathrm{FC}$ & $\mathrm{G} / \mathrm{G}$ & 0.71 & 0.69 & 0.60 & 0.50 & 0.30 & 0.16 & 0.06 \\
\hline 17 & $\mathrm{FC}$ & $\mathrm{G} / \mathrm{G}$ & 0.71 & 0.69 & 0.60 & 0.50 & 0.30 & 0.16 & 0.06 \\
\hline 18 & $\mathrm{FA} 2$ & $\mathrm{G} / \mathrm{G}$ & 0.73 & 0.71 & 0.62 & 0.51 & 0.31 & 0.14 & 0.03 \\
\hline 19 & $\mathrm{SC}$ & $\mathrm{G} / \mathrm{G}$ & 0.76 & 0.73 & 0.62 & 0.48 & 0.26 & 0.12 & 0.04 \\
\hline 20 & $\mathrm{SC}$ & $\mathrm{G} / \mathrm{G}$ & 0.76 & 0.73 & 0.62 & 0.48 & 0.26 & 0.12 & 0.04 \\
\hline 21 & FA1 & $\mathrm{G} / \mathrm{G}$ & 1.63 & 1.59 & 1.44 & 1.25 & 0.88 & 0.52 & 0.21 \\
\hline 22 & FA3 & $\mathrm{G} / \mathrm{G}$ & 2.04 & 2.00 & 1.83 & 1.61 & 1.17 & 0.71 & 0.28 \\
\hline 23 & $\mathrm{COM}$ & $\mathrm{H} / \mathrm{H}$ & 0.68 & 0.67 & 0.60 & 0.53 & 0.37 & 0.23 & 0.10 \\
\hline 24 & $\mathrm{FC}$ & $\mathrm{J} / \mathrm{J}$ & 1.02 & 0.99 & 0.89 & 0.77 & 0.52 & 0.30 & 0.13 \\
\hline 25 & $\mathrm{FC}$ & $\mathrm{H} / \mathrm{I}$ & -0.69 & -0.57 & -0.32 & -0.18 & -0.06 & -0.02 & -0.01 \\
\hline Total & & & 18. 29 & 17.89 & 15.81 & 13. 28 & 8.40 & 4. 54 & 1.76 \\
\hline
\end{tabular}

Type of marriage in each family: FC, first cousin marriage; SC, second cousin marriage; COM, complicated intermarriage; FA, family with WRN. (FA2, O family; FA3, H family.) Allele length; A. 162 bp; B, 164 bp; G, 174 bp; H, 176 bp; I, 178 bp; J, 180 bp.

seemed to be nonconsanguineous. Two patients, II-1 and II-2, received mutative haplotypes, E-G-D from the father and C-G-D from the mother. Meiotic recombinations were thought to have occurred at two loci, between D8S339 and ANK1, and between D8D360 and D8S339 in patient II-2. The younger sister, II-3, seemed to be healthy and normal on clinical examination, however she must have been a carrier because of inheritance of the mutative haplotype. It was unlikely that 


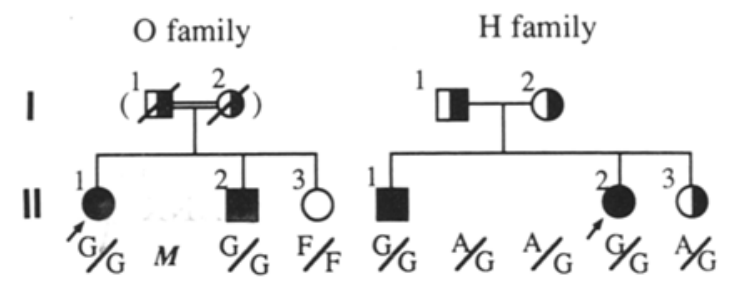

Fig. 1. Microsatellite polymorphism of D8S339 to genomic DNA from members of $\mathrm{O}$ and $\mathrm{H}$ families. Arrows indicate the probands. Allele length for D8S239; $\mathrm{A}=162 \mathrm{bp}, \mathrm{F}=172 \mathrm{bp}, \mathrm{G}=174 \mathrm{bp} . \quad \mathrm{M}$ is a control marker.

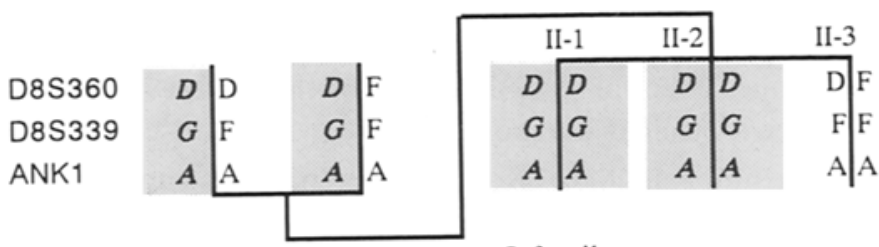

O family

D8S360

D8S339

ANK1

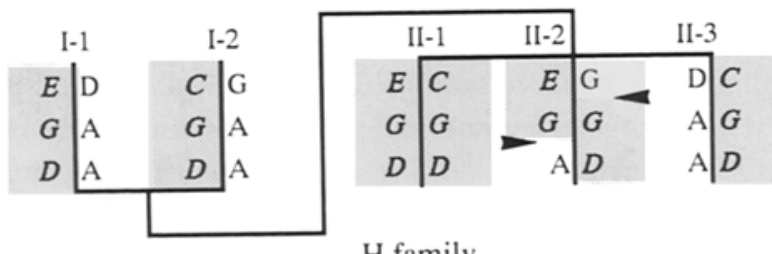

$\mathrm{H}$ family

Fig. 2. D8S360, D8S339, and ANK1 locus segregation in $\mathrm{O}$ and $\mathrm{H}$ families. Arrows indicate the sites of possible recombination. Allele length for D8S360; $\mathrm{C}=95$ bp, $\mathrm{D}=97 \mathrm{bp}, \mathrm{E}=99 \mathrm{bp}, \mathrm{F}=101 \mathrm{bp}, \mathrm{G}=103 \mathrm{bp}$. For $\mathrm{D} 8 \mathrm{~S} 339$; $\mathrm{A}=162 \mathrm{bp}$, $\mathrm{F}=172 \mathrm{bp}, \mathrm{G}=174 \mathrm{bp}$. For $\mathrm{ANK} 1 ; \mathrm{A}=107 \mathrm{bp}, \mathrm{D}=113 \mathrm{bp}$. In $\mathrm{O}$ family it is not clear whether father I-1 has haplotype D-F-A, because DNA samples from parents were not obtained.

double recombinations would occur between D8S360 and D8S339 or between D8S339 and ANK1.

Vol. 39, No. 4, 1994 


\section{DISCUSSION}

Thomas et al. (1993) genotyped Japanese families with WS and reported that the WRN locus might be located between D8S87 and ANK1 and that a DNA marker D8S360 was closely linked to the WRN locus at a recombination fraction of 0.006 with maximum lod score of 16.5. Here, we studied different Japanese families with WS from Thomas' group and confirmed their results using homozygosity mapping techniques as described by Lander and Botstein (1987). Although only $\mathrm{H}$ family was not from a consanguineous marriage, both affected siblings were homozygous for the $\mathrm{G}$ allele of D8S339, which is the most common allele associated with the mutative WRN gene (Table 1), and their parents were from a small town in the countryside of Hyogo prefecture. Therefore, it is likely that the parents may have had a common ancestor chromosome. One obligate recombination was found in No. 25 family from a cousin marriage. In order to exclude allelic heterogeneity, we examined the possibility of misdiagnosis of the affected individual, missampling of DNA, mistyping of the result and other human errors, and genotyped her using other microsatellites of the WRN region (data not shown). Finally we confirmed one recombination in this family. This recombination site is useful in order to reduce the critical WRN region. Thomas et al. (1993) also obtained similar results that D8S339 showed one obligate recombination in one out of 24 inbred families. So far D8S339 is one of the closest markers to the WRN locus and is useful for molecular diagnosis.

Since WS is an autosomal recessive disease, patients should be homozygous for the mutative WRN gene, and the parents heterozygous carriers. In $\mathrm{H}$ family, the genotype indicate that unaffected sibling II-3 was a carrier for the WRN mutation. Two markers, D8S360 and ANK1, on both sides of the WRN locus were informative in this family, so the reliability of the diagnosis was more than $99 \%$. Two recombinations between the WRN mutation and D8S336 or ANK1 were observed, but no obligate recombination between the WRN mutation and D8S339 was detected in these families. Thus we can identify the mutative allele through the generations in both pedigrees. We conclude that D8S360 is one of the markers tightly linked to WRN mutation and that haplotype analysis of WRN families using these markers can allow carrier detection and presymptomatic diagnosis with high accuracy.

The WRN locus was estimated by looking for the homozygosity region in inbred pedigrees, and by looking for the obligate recombination site in pedigrees without consanguinity. The result that 13 out of 24 families were homozygous for the allele $G$ indicates a linkage disequilibrium between the WRN locus and D8S339, while the studies of Thomas et al. (1993) did not demonstrate it. We do not know the reason for this discrepancy, because the total numbers of family members were almost the same. One possibility is that our families originated 
mainly from the restricted western area of Japan in contrast to Thomas' families. The region in which linkage disequilibrium between the disease locus and the flanking marker can be detected is usually within 1-2 cM. We predict that D8S339 is located close to the WRN locus and use this marker as a STS (sequence tagged site) marker to make a detailed physical map.

Acknowledgments We thank the following individuals for assisting in sampling: Y. Fujiwara, K.-I. Fukuchi, K. Hiwada, Y. Hosokawa, H. Ishiwata, S. Kiso, T. Maeda, T. Matsumura, T. Miyagi, T. Murakami, S. Murano, N. Niikawa, K. Sahashi, T. Saida, S. Tamaki, N. Utsu, B. Ueno, A. Wakayama, M. Yanagawa, and S. Yoshida. This work was partly supported by a Grantin-Aid for Creative Basic Research (Human Genome Program) from the Ministry of Education, Science and Culture of Japan, and a grant from the Research Project on Health and Aging.

\section{REFERENCES}

Epstein C, Martin G, Schultz AL, Motulsky AG (1966): Werner's syndrome: A review of its symptomatology, natural history, pathologic features, genetics and relationship to the natural aging process. Medicine 45: 177-221

Goto M, Rubenstein M, Weber J, Woods K, Drayna D (1992): Genetic linkage of Werner's syndrome to five markers on chromosome 8. Nature 355: 735-738

Kamino K, Nakura J, Kihara K, Ye L, Nagano K, Ohta T, Jinno Y, Niikawa N, Miki T, Ogihara $T$ (1993): Population variation in the dinucleotide repeat polymorphism at the D8S360 locus. Hum Mol Genet 2: 1751

Lander ES, Botstein D (1987): Homozygosity mapping: a way to map human recessive traits with the DNA of inbred children. Science 236: 1567-1570

Lathrop G, Lalouel J-M, Julier C, Ott J (1984): Multilocus linkage analysis in human: detection of linkage and estimation of recombination. Proc Natl Acad Sci USA 81 : 3443-3446

Nagano K, Nakura J, Kihara K, Ye L, Kamino K, Mitsuda M, Ohta T, Jinno Y, Niikawa N, Miki T, Ogihara T (1993): Isolation and mapping of microsatellites from a library microdissected from the Werner's syndrome region, 8p11.2-p22. Jpn J Human Genet 38: 391-397

Nakura J, Miki T, Nagano K, Kihara K, Ye L, Kamino K, Fujiwara Y, Yoshida S, Murano S, Fukuchi K, Wijsman EM, Martin G, Schellenberg GD, Ogihara T (1993): Close linkage of the gene for Werner's syndrome to ANK1 and D8S87 on the short arm of chromosome 8 . Gerontology 39 (suppl 1): 11-15

Nakura J, Wijsman EM, Miki T, Kamino K, Yu C-H, Oshima J, Fukuchi K, Weber JL, Piussan C, Melaragno MI, Epstein CJ, Scappaticci S, Fraccaro M, Matsumura T, Murano S, Yoshida S, Fujiwara Y, Saida T, Ogihara T, Martin GM, Schellenberg GD (1994): Homozygosity mapping of the Werner's syndrome locus. Genomics, in press

Polymeropoulos MH, Rath DS, Xiao H, Merril CR (1991): Dinucleotide repeat polymorphism at the human ankyrin gene (ANK1). Nucleic Acids Res 19: 969

Schellenberg GD, Martin GM, Wijsman EM, Nakura J, Miki T, Ogihara T (1992): Homozygosity mapping and Werner's syndrome. Lancet 338: 1002

Thomas W, Rubenstein M, Goto M, Drayna D (1993): A genetic analysis of the Werner syndrome region on human chromosome 8p. Genomics 16: 685-690

Yu C-H, Oshima J, Goddard KAB, Miki T, Nakura J, Ogihara T, Poot M, Hoehn H, Fraccaro M, Piussan C, Martin G, Schellenberg GD, Wijsman EM (1994): Linkage disequilibrium and haplotype studies of chromosome 8p11.1-21.1 markers and Werner syndrome. Am J Hum Genet 55: 356-364 